\title{
Formation Of Superficial Palmar Arch:A Cadaveric Study With Its Clinical Significances
}

\author{
Mamatha Tonse ${ }^{1}$, Rajalakshmi Rai ${ }^{1}$, Vasudha Saralaya ${ }^{1}$, Rajanigandha \\ Vadgaonkar ${ }^{1}$, Ashwin R Rai ${ }^{1}$, Roshni Sadashiv ${ }^{2}$ \\ ${ }^{1}$ Department of Anatomy, Kasturba Medical College Mangalore, Manipal University, INDIA \\ ${ }^{2}$ Department of Anatomy, Devaraja Aras Medical College, Kolar, INDIA
}

\begin{abstract}
The vasculature of the hand has been a topic of anatomical interest because of wide range of variations in the formation and distribution of palmar arches. In the present study we have emphasized on the varying pattern of the formation and branching pattern of the superficial palmar arch (SPA) in cadaveric human hands. The study was conducted in 42 formalin fixed human cadaveric hands and different presentations were noted. The classic formation of the SPA was noted in $76.6 \%$ of the specimens and mostly on the right hand. The other variants noted were SPA completed by the first dorsal metacarpal artery and SPA formed between median and ulnar artery. Incomplete SPA ending in the thenar muscles and an abrupt end between the index and middle finger were also noted in the present study. The existence of both common and rare anatomic variations in the formation of superficial palmar arch as well as the absence of collateral circulation between ulnar and radial arteries necessitates the proper knowledge of vasculature of the hand in order to avoid or minimize the risk of complications during vascular surgeries or reconstructive surgeries in the hand.
\end{abstract}

Key words: anatomical variations, superficial palmar arch, radial artery, ulnar artery, palmar vasculature

\section{Introduction}

Because of innovations in modern microsurgical techniques a better understanding of vascular patterns of hand becomes more validated (Gellman et al, 2001). Arterial supply of the hand is by superficial and deep palmar arches which are placed on the palmar aspect of the hand (Snell, 2004).Superficial palmar arch (SPA) is usually formed by the ulnar artery and completed by a branch from the radial artery, deep to the palmar aponeurosis. The classic type of SPA is the one which is formed by the ulnar artery and completed by the superficial palmar branch of radial artery (Williams et al, 1989). Several authors have classified the SPA according to the contribution by radial, ulnar or median arteries or their branches (Keen, 1961; Murakami et al, 1969; Coleman \& Anson, 1961; Bilge 2006).Murakami and coworkers (1969) proposed a classification based on the origin and proximal course of the princeps pollicis artery (PPA). Agur and Lee (1991) describe a dorsalis policis artery, a branch of radial artery, contributing to the formation of SPA. Fazan et al, (2004) observed above type of variation in $33 \%$ of the left hands and $20 \%$ of the right hands of their study series. Though the variations in the formation of SPA are well documented in the medical literature it is necessary to record variations time and again as the vasculature of hand is surgically significant.

\section{Materials \& Method}

The present study was conducted in the department of Anatomy of KMC Mangalore affiliated to Manipal University. The study was carried in 42formalin fixed cadaveric upper limbs (bilaterally) for the past 2 years. The course of ulnar and radial arteries in the palm was noted and formation of superficial palmar arch was studied and variations were recorded.

\section{Results}

Among the total 42 specimens studied, classic formation of SPA between the superficial branch of ulnar artery and superficial palmar branch of radial artery was observed in $76 \%$ of the cases. It was predominantly seen in right hands. There were no double arches except that in one case a small arterial arcade was observed between a branch to the radial side of index finger and the adjacent common digital artery (Fig 1). The remaining variant patterns are recorded below along with the classic type.

\section{Type I: Radio-ulnar type of complete arch}

a. In60\% of the cases studied SPA was formed by ulnar artery \& superficial palmar branch of radial artery (Fig 1).

b. In $6 \%$ of the cases SPA was formed between ulnar artery \& arteria radialis indicis of radial artery (Fig 2). 
c. In $10 \%$ of the cases studied SPA was formed between ulnar artery and first dorsal metacarpal branch (FDMA) of radial artery (Fig 3).

\section{Type 2: Mediano-ulnar type of complete arch}

In $12 \%$ of the specimens SPA was formed between median artery \& ulnar artery (Fig 4).

Type 3: Incomplete arch

Incomplete SPA formed by ulnar artery was noted in $12 \%$ of the specimens studied. It was ending in the thenar muscles and arteria radialis indicis \& arteria princeps pollicis were arising from the SPA (Fig 5).

\section{Discussion}

It is essential for a hand surgeon to recognize the functional arterial arch before surgical procedures in the palm in order to maintain the vascularity of the hand and digits (Khan et al, 1998). Pierer et al., describe that the second metacarpal bone is often used as a graft for reconstruction of thumb or index finger defects (Pierer, 1992). The nutrient vessels to this bone originate from the radial artery or from the deep palmar arch. Hence any variation in the collateral blood flow between ulnar and radial artery become surgically significant. Superficial palmar arch provides this collateral circulation between radial and ulnar artery. The contribution of forearm arteries in the formation of superficial palmar arch has been recorded by several authors (Loukas et al, 2005; Patnaik et al, 2002; Al-Turk \& Metcalf, 1984). They are classified as either complete arches or incomplete arches and reported percentage of both the types are shown in table 1. Among the complete arches radioulnar type was predominating in all except the reports of Adachi and Coleman \& Anson wherein ulnar type of complete arch was reportedly higher.In the present study ulnar type of complete arch was not observed and radioulnar type of complete SPA was seen in $76 \%$ of the cases studied.

Developmental evidence suggests that on reaching the hand the ulnar artery links with the superficial palmar plexus from which superficial palmar arch originates, while the median artery loses its distal connection and is reduced to a small vessel (Williams, 1995). According to Bergman, et al. the superficial arch can be reinforced by a large median artery which arises frequently from the anterior interosseus artery (Bergman et al, 1988). The proportion of hands in which the median artery made a contribution to the superficial palmar arch was reported as $6 \%$ by Anitha et al., (2011). Rodriguez et al described the palmer type of median artery, representing its embryonic pattern as large, long and reaching the palm (Rodriguez et al, 1999). They suggest that radial artery acquires its final state by stage 21 of the embryo and any variations in the formation of SPA may be due to persistence or enlargement of initial network of vessels which normally regress or remain as capillaries. Embryological basis for high origin of superficial ulnar artery and its contribution in the formation of SPA has been reported by Natsis et al. (2006) and Reddy \&Vollala (2007). Ikeda et al., (1988) also suggest that an inhibition of the development of the vessels at different stages of the embryonic period may be the causes of arterial congenital anomalies.

The branch of radial artery which contributes to the completion of SPA varies. In the present study in $10 \%$ of the cases SPA was completed by first dorsal metacarpal artery in (Fig. 2) which is not reported by the previously mentioned authors. Arteria princeps pollicis \& arteria radialis indicis were branches from first dorsal metacarpal arteries. This type of variation makes it more prone for injuries while evacuating the abscess in the thenar space. In $10 \%$ of cases SPA is completed by arteria princeps pollicis and in remaining $6 \%$ cases SPA is completed by arteria radialis indicis as shown in figure 5 .

In the present study median artery contributed to the formation of superficial palmar arch in $13 \%$ of the cases (Fig. 4). It provided common digital branches to adjacent sides of little, ring, middle \& index fingers along with anarteria radialis indicis \& princeps pollicis. However, in one specimen a common trunk was dividing to give arteria radialis indicis, a branch to the medial side of thumb and a branch to lateral side of thumb.

As Ruengsakulrach and co-authors suggest awareness about variation in collateral circulation, like the occurrence of an incomplete SPA, becomes necessary while harvesting the radial artery for arterial by-pass channels or while harvesting the free Radial Forearm Flap (Ruengsakulrach et al, 2001). As discussed by Rao et al., (2010) if ulnar and radial arteries fail to communicate, manifestations of claudication, rest pain or gangrene may develop in case of occlusion of ulnar artery since there will not be collateral blood flow. This can be applied to the incomplete arch seen in the present study where it was formed only by ulnar artery as shown in Figure 5.

\section{Conclusion}

The existence of both common and rare anatomic variations in the formation of superficial palmar arch as well as the absence of collateral circulation between ulnar and radial arteries necessitates the proper knowledge of vasculature of the hand in order to avoid or minimize the risk of complications during vascular surgeries or reconstructive surgeries in the hand. 


\section{References:}

[1] Agur AMR, Lee MJ. 1991. Grant's Atlas of Anatomy. 9th edition, Baltimore: Williams \& Wilkins.

[2] Al-Turk M, Metcalf WK. 1984. A study of the superficial palmar arteries using the doppler ultrasonic flowmeter. Journal of Anatomy 138(1):27-32.

[3] Anitha T, Kalbande S, Dombe D et al.2011.Variations in the formation of superficial palmar arch and its clinical significance in hand surgeries.Int J Biol Med Res2(2):543-46.

[4] Bergman RA, Thompson SA, Afifi AK, Saadeh FA. 1988. Compendium of human anatomical variations. Munich: Urban and Schwarzenberg.

[5] Bilge O, Pinar Y, Ozer MA, Govsa F. 2006. A morphometric study on the superficial palmar arch of the hand. SurgRadiolAnat 28 (4):343-50.

[6] Coleman SS, Anson BJ. 1961. Arterial patterns in the hand based upon a study of 650 specimens. SurgGynecolObstet 113:409-24.

[7] Fazan VP, Borges CT, Da Silva JH, Caetano AG, Filho OA. 2004. Superficial palmar arch: an arterial diameter study. J Anat 204:307-11.

[8] Gellman H, Botte MJ, Shankwiler J et al. 2001. Arterial patterns of the deep and superficial palmar arches. ClinOrthopRelat Res $383 ; 41-6$.

[9] Ikeda A, Ugawa A, Kazihara Y, Hamada N. 1988. Arterial patterns in the hand based on three-dimensional analysis of 220 cadaver hands. J Hand Surg 13:501-9.

[10] Keen JA. 1961. Study of the arterial variations in the limbs, with special reference to symmetry of vascular patterns. Am J Anat 108:245-61.

[11] Khan K, Riaz M, Small JO. 1998. The use of the second dorsal metacarpal artery for vascularized bone graft: An anatomical study. J Hand Surg Br 23:308-10.

[12] Loukas M, Holdman D, Holdman S. 2005. Anatomical variations of the superficial and deep palmar arches, Folia Morphologica (Warsz) 64(2):78-83

[13] Murakami T, Takaya K, Outi H. 1969. The origin, course and distribution of arteries to the thumb, with special reference to the socalled arteriaprincepspollicis. Okajimas Folia AnatJpn 46:123-37.

[14] Natsis K, Papadopoulou AL, Paraskevas G, Totlis T, Tsi P. 2006. High origin of a superficial ulnar artery arising from the axillary artery: anatomy, embryology, clinical significance and a review of the literature. Folia Morphol 65:400-5.

[15] Patnaik VVG, Kalsey G, Singla RK. 2002. Palmar arterial arches- a morphological study. J AnatSocInd51(2):187-93.

[16] Pierer G, Steffen J, Hoflehner H. 1992. The vascular blood supply of the second metacarpal bone: anatomic basis for a new vascularized bone graft in hand surgery: An anatomical study in cadavers. SurgRadiolAnat 14(2):103-12.

[17] Rao S, Vollala VR, Pamidi N, Nagabhooshana S, Potu BK. 2010. Variant formation and distribution of the superficial palmar arch. Indian J PlastSurg 43: 116-7.

[18] Reddy S, Vollala VR. 2007. The superficial ulnar artery: development and clinical significance. J Vasc Bras 6(3):285-8.

[19] Rodriguez MN, Sanudo JR, Vazquez T et al. 1999. Median artery revisited. J O Anat 195: 57-63.

[20] Ruengsakulrach P, Eizenberg N, Fahrer C, Fahrer M, Buxton BF. 2001. Surgical implications of variations in hand collateral circulation: anatomy revisited. J ThoracCardiovascSurg 122: 682-6.

[21] Snell RS. 2004. Clinical Anatomy. 7th edition, Baltimore: Lippincott Williams and Wilkins.

[22] Williams PL, Warwick R, Dyson M, Bannister LH. 1989. Gray's Anatomy, 37th edition, London, Churchill Livingstone, 319.

[23] Williams PL. 1995. Gray's anatomy. 38th edition, New York: Churchill Livingstone, 1542.

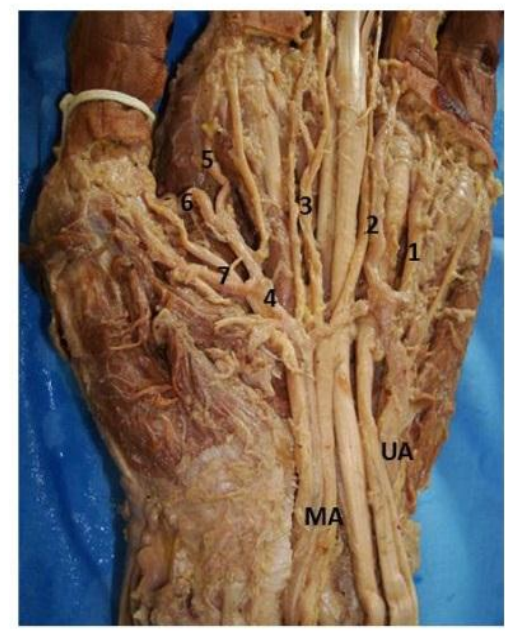

Fig 4: Dissected left palm sowing formation of superficial palmar arch between median artery \& ulnar artery; UA - ulnar artery MA - median artery $1,2,3$ - common digital arteries to the adjacent sides of little, ring, middle \& index fingers, $4-$ common trunk dividing to arteria radialicis indicis (5), a branch to medial side of thumb (6), and a branch to lateral side of thumb (7)

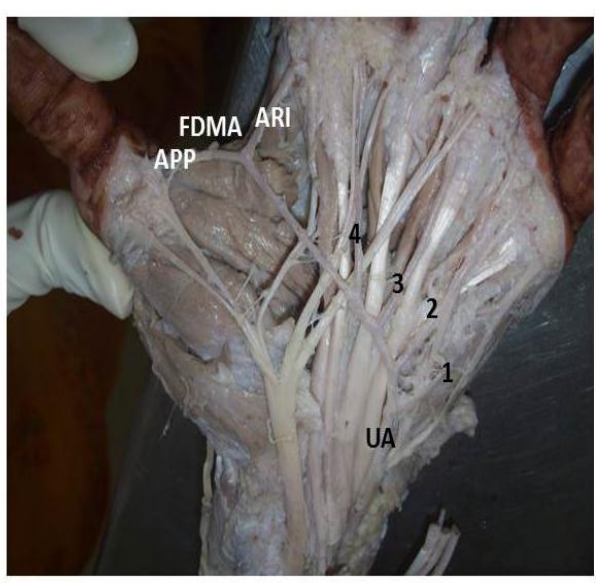

Fig 3: Dissected left palm showing the completion of SPA by first dorsal metacarpal artery. UA - superficial branch of ulnar artery 1 - proper digital branch to the ulnar side of little finger 2,3,4-common digital branches to the adjacent sides of little, ring. middle \& index fingers ARI - arteria radialis indicis APP - arteria princeps pollicis FDMA - first dorsa metacarpal artery 


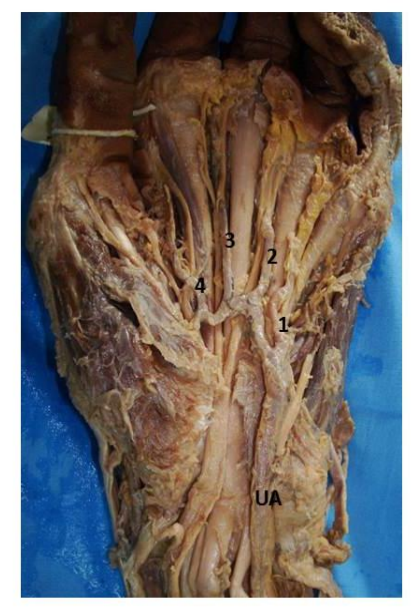

Fig 2: Dissected left hand showing SPA between arteria radialis indicis \& ulnar artery $1,2,3$ - common digital branch o the adjacent sides of little, ring, middle \& index finger 4 - common trunk dividing to arteria radialicis indicis \& princeps pollicis

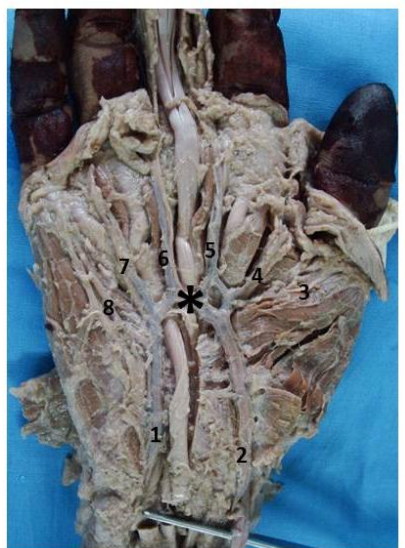

Fig 1: Dissected right palm showing the completion of SPA by superficial palm branch of radial artery. 1. superficial branch of ulnar artery 2 . superficial palmar branch of radial artery 3 . artery to the radial side of thumb 4 . common digital artery to the ulnar side of thumb \& radial side of index finger 5, 6,7-common digital branch to the adjacent sides of index, middle, ring \& little fingers 8 - proper digital branch to the ulnar side of little finger

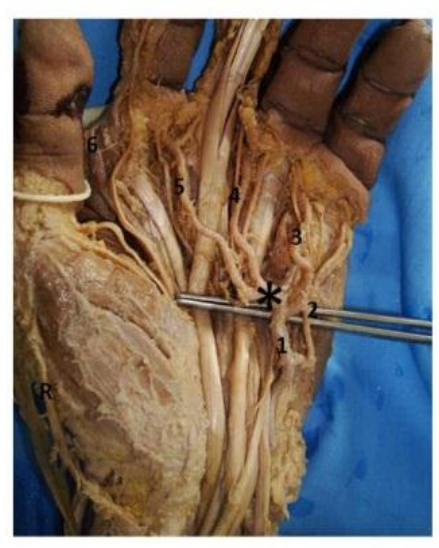

Fig 5 : Dissected left palm showing incomplete superficial palmar arch (*) terminating at the midpalm level; 1 .superficial branch of ulnar artery 2. digital branch to medial side of little finger $3,4,5$ - common digital branches to adjacent sides of little, ring, middle \& index fingers 6 . arteria radialis indicis $\mathrm{R}$ - Radia artery passing to the dorsum of hand 